Copyright (C) 2021 University of Bucharest Printed in Romania. All rights reserved

ISSN print: $1224-5984$

ISSN online: $2248-3942$
Rom Biotechnol Lett. 2021; 26(6): 3090-3094 doi: $10.25083 / \mathrm{rbl} / 26.6 / 3090-3094$

Received for publication, October, 30, 2020

Accepted, November, 8, 2021

Original paper

\title{
Isolation and phenotypic characterization of Gallibacterium anatis biovar haemolytica from a hen with hemorrhagic ooforitis
}

\author{
IONUT SORESCU ${ }^{1}$, LUMINITA MARIA ROMASCU ${ }^{1}$, MARIA IONESCU ${ }^{1}$, \\ ANDREI POPOVICI ${ }^{1}$, COSTIN STOICA ${ }^{2}$, FLORICA BARBUCEANU ${ }^{1}$ \\ ${ }^{1}$ Institute of Diagnosis and Animal Health, Bacteriology Laboratory, 63 Dr. Staicovici, 050557 Bucharest, \\ Romania; +4 0749151806 \\ ${ }^{2}$ Romvac Company, 7 Soseaua Centurii, Voluntari 077190, Ilfov, Romania
}

\begin{abstract}
Objective: the isolation and phenotypically identification of a Gallibacterium anatis biovar haemolytica strain from a hen with hemorrhagic ooforitis; the antimicrobial susceptibility testing of this isolate.

Methods and results: a strain of $G$. anatis biovar haemolytica, was isolated and phenotypic identified by morphological, cultural and biochemical characters examination, with API 20 E, API 20 NE, API STAPH, API ZYM tests and ABIS online software. The antimicrobial susceptibility of the isolate was performed using the standard disk diffusion method.

Conclusions: a strain of G. anatis biovar haemolytica was isolated and phenotypically identified from a hen. From our knowledge, this is the first reporting in Romania of isolation and identification of $G$. anatis biovar haemolytica. The Gah IDSA 161 strain could be phenotypic identified only by ABIS on line software, Pasteurellaceae Database version, unifying the results of four API kits and other biochemical tests. The isolate showed a multi-drug resistant profile to tetracyclines (tetracycline, oxitetracycline, doxicyclin), floroquinolones (enrofloxacin, ciprofloxacin), ampicillin, trimethoprim, nalidixic acid, clindamycin, and it was susceptible to sulfonamide, sulfomethoxazole/trimethoprim, gentamicin, cephalothin, streptomycin, amoxicilin/clavulanic acid.
\end{abstract}

Keywords Gallibacterium anatis biovar haemolytica, hen, phenotypic identification, antimicrobial susceptibility testing

To cite this article: SORESCU I, ROMASCU LM, IONESCU M, POPOVICI A, STOICA C, BARBUCEANU F. Isolation and phenotypic characterization of Gallibacterium anatis biovar haemolytica from a hen with hemorrhagic ooforitis. Rom Biotechnol Lett. 2021; 26(6): 3090-3094. DOI: $10.25083 / \mathrm{rbl} / 26.6 / 3090-3094$.

*Corresponding author: IONUT SORESCU, Institute of Diagnosis and Animal Health, Bacteriology Laboratory, 63 Dr. Staicovici, 050557 Bucharest, Romania; +4 0749151806.

E-mail: ionutsorescu68@gmail.com 


\section{Introduction}

Gallibacterium anatis is part of the normal chicken microbiota in the upper respiratory, lower genital and terminal digestive tracts (Christensen et al., 2003; Bojesen et al., 2003a). However, G. anatis is define as an opportunistic pathogen associated with pathological changes in the reproductive organs (oophoritis, follicular hemorrhage, salpingitis), gastrointestinal (inflammation of intestine and peritoneum, hepatic necrosis) and respiratory systems (necrosis, inflammation), septicaemia and pericarditis (Paudel et al., 2013; Persson and Bojesen, 2015; Krishnegowda et al., 2020). The pathogenicity of G. anatis is determined by virulence determinants of bacterial strain (toxin A, outer membrane vesicles, F 17-like fimbriae, capsule, metalloproteases, biofilm formation, hemagglutinin) and route of infection (Persson and Bojesen, 2015; Krishnegowda et al., 2020). The physiological status of host (stress, immune status, age, hormones), co-infection with other pathogens (Escherichia coli, Avibacterium paragallinarum, Mycoplasma gallisepticum, infectious bronchitis virus) and abrupt changes in environment (cold stress, deficient nutrition, poor ventilation etc.) exacerbate the disease (Krishnegowda et al., 2020). Diagnosis of the Galibacterium anatis infection is based on isolation and identification by phenotypic characterization (Christensen et al., 2003). Other tools have been used, also, for the bacterial identification: matrix-assisted laser desorption/ionization time-of-flight (MALDI-TOF) mass spectrometry, gyrB gene-based quantitative PCR (qPCR) assay, PCR restriction fragment length polymorphism (PCR-RFLP) assay, fluorescence in situ hybridization (FISH) (Bojesen et al., 2003b; Alispahic et al., 2012; Wang et al., 2016; El-Adawy et al., 2018).

The genus Gallibacterium has four named species $(G$. anatis, G. mellopsittaci, G. trehalosifermentans and $G$. salpingitidis), three Gallibacterium genomospecies (1, 2 and 3) and un unnamed group V (Christensen et al., 2003; Bisgaard et al., 2009). Genus Gallibacterium belongs Pasteurellaceae family (Christensen et al., 2003; Bisgaard et al., 2009). G. anatis is divided in two biovars: haemolytica and anatis. G. anatis bv. haemolytica comprises $\beta$-haemolytic, Darabinose and L-fucose positive isolates (includes strains from former biovars 1, 3, 4, 11, 12, 15, 17-20, 22, 24 of the avian [Pasteurella haemolytica]-'Actinobacillus salpingitidis' complex). G. anatis bv. anatis comprises non-haemolytic, trehalose-positive and D-arabinose-, L-fucose-, maltose- and dextrin-negative isolates (includes strains from former $P$. anatis) (Christensen et al., 2003). G. anatis has been isolated from domestic and non-domestic birds (chicken, turkey, goose, duck, budgerigar, parrot, peacock, partridge, pheasant, guinea fowls), other domestic animals (cattle, pigs, sheep, horse and rabbits) (Christensen et al., 2003; Rzewuska et al., 2007; Krishnegowda et al., 2020) and human (an immunocompromised women with bacteremia and diarrhea) (Aubin et al., 2013). G. anatis is distributed in Europe (Poland,
Germany, Denmark, Switzerland, Norway, England, Sweden, Austria, Czech Republic), Africa (Egypt), Asia (Iran), Australia, North (Mexic) and South America (Rzewuska et al., 2007; Persson and Bojesen, 2015; Krishnegowda et al., 2020).

The aim of our work was to communicate the isolation and phenotypically identification of a $G$. anatis biovar haemolytica strain from a hen with hemorrhagic ooforitis and antimicrobial susceptibility testing of this isolate. From our knowledge, this is the first reporting of $G$. anatis biovar haemolytica isolation and identification in Romania.

\section{Materials and Methods}

\section{Pathological material}

Heart, lung, spleen, liver, kidney, ileum and genital tract samples from a hen were collected for bacteriological examination. Hemorrhagic ooforitis was observed. The hen came from a 30 birds flock, Ilfov county, Romania.

\section{Isolation of bacterial strains}

The specimens were streaked on nutrient agar (Oxoid) supplemented with 5\% sheep blood and inoculated media were incubated at $37^{\circ} \mathrm{C}$ for $24-48$ hours in aerobic conditions. The colonies with large $\beta$-haemolysis zone from blood agar plates were investigated for cell morphology in Gram-staining slides and inoculated in nutrient broth (Oxoid) supplemented with 5\% horse serum and $3 \%$ glucose for isolation of bacterial strain.

\section{Identification of bacterial strains}

Phenotypic identification of isolated bacterial strain was performed by morphological, cultural and biochemical characters examination, according with Christensen et al. 2003, Christensen et al. 2007, Rzewuska et al., 2007, Bisgaard et al., 2009 and ABIS on line software, Stoica and Sorescu, 2020. Cell morphology was observed in Gramstaining slides, mobility was appreciated in semisolid medium (Mobility-Indol-Urea medium) and cultural characters were investigated with blood nutrient agar and nutrient broth with serum and glucose. Biochemical characters of the isolated strain were determined using MIU, TSI (Triple-Sugar-Iron) and Simmon's citrate media, API 20 E, API 20 NE, API STAPH and API ZYM tests (bioMerieux, France), according to the manufacturers instructions. The catalase $\left(3 \% \mathrm{H}_{2} \mathrm{O}\right)$, oxidase (Sigma) and ONPG (Oxoid) tests were performed, also.

\section{Antimicrobial susceptibility}

The antimicrobial susceptibility of the isolated strain was performed using the standard disk diffusion method according to the Clinical Laboratory Standards Institute (CLSI) 2002 (M31-A2), CLSI VET08-ED4:2018 (zone diameter for Actinobacillus pleuropneumoniae) and CLSI 2020 (M100, ed. 30, zone diameter for Haemophilus influenzae and $H$. parainfluenzae). Mueller Hinton Agar with 5\% sheep blood (BioMaxima, Poland) and disks containing specified amounts of antibiotics (Oxoid) were used. The plates were incubated at $37^{\circ} \mathrm{C}, 24$ hours, in aerobic conditions. 


\section{Results and discussion}

A strong $\beta$-haemolytic strain was isolated from heart, ovaries, lung and spleen of a hen with hemorrhagic ooforitis. This strain wasn't isolated from liver, kidney or ileum. A non-haemolytic Escherichia coli strain was isolated, from ovaries, also.

The taxonomic classification of isolated bacterial strain in Gallibacterium anatis biovar haemolytica was performed by morphologically, culturally and biochemically characteristics. It is Gram-negative, polymorph, non-motile rod, shorter or cocobacillar on blood agar media and longer rod in serum glucose broth. The bacteria occurs singly, in pairs or, in liquid media, in short chains. Colonies are strong $\beta$-haemolytic, circular with regulated edges, transparent/ semi-transparent, smooth, non-pigmented, up to $1 \mathrm{~mm}$ in diameter after 24 hours or 1,5-2.0 mm after 48 hours of aerobic incubation at $37{ }^{\circ} \mathrm{C}$ on agar media (nutrient agar, Columbia agar, Tryptone Soya agar) supplemented with 5\% sheep blood (Fig. 1). It determines small, pinpoint, opaque, pink or red colonies on MacConkey agar after 24-48 hours of incubation. No V-factor requirement. The strain grow moderate, with small, granular deposit and weak turbidity in nutrient broth supplemented with 5\% horse serum and 3\% glucose after 24-48 hours of incubation. It grows better on Brain Heart Infusion (Oxoid) broth supplemented with 5\% horse serum. Positive reactions are obtained for catalase, oxidase and ONPG tests. Nitrate is reduced. $\alpha$-glucosidase (PNPG), alkaline phosphatase, acid phosphatase, esterase (C4), esterase-lipase (C8), leucine arylamidase and naphtolphosphohidrolase tests are positive. Acid is formed without gas from D-glucose (could be weak), D-mannitol, inositol, D-sorbitol, L-rhamnose (29 hours of incubation), D-sucrose, D-fructose, D-mannose, D-trehalose, D-xilose, Nacetylglucosamine. Negative in Simmon's citrate, TSI growth, indole and urease tests in MIU. Negative tests are further observed with lipase (C14), valine arylamidase, cystine arylamidase, trypsine, $\alpha$-chymotrypsine, $\alpha$ galactosidase, $\beta$-glucuronidase, $\beta$-glucosidase, $\mathrm{N}$-acetyl- $\beta$ glucosaminidase, $\alpha$-mannosidase, $\alpha$-fucosidase, arginin dihydrolase, lysine decarboxilase, ornithine decarboxilase, tryptophane deaminase, Voges-Proskauer (acetoin production) and gelatinase. Acid is not produced from Dmelibiose, amygdalin, L-arabinose, D-maltose, lactose, xylitol, D-rafinose and metil $\alpha$-D glucopyranoside.

API 20E profile was unacceptable by apiweb ${ }^{\mathrm{TM}}$ API 20 E V4.1 soft, but with Pasteurella pneumotropical Mannheimia haemolytica as significant taxa. Good identification was obtined by API $20 \mathrm{NE}$ by apiweb ${ }^{\mathrm{TM}}$ API 20 NE V7.0 soft, with Mannheimia haemolytical Pasteurella trehalosi, 91,8\% ID. The result of ABIS online identification, Pasteurellaceae 2.2.9.-062020 Database version, using the data of all above kits and tests, was Gallibacterium anatis biovar haemolytica, similarity $91,8 \%$. Similarity \% for ABIS is the similarity with taxa from the database, wich containing a matrix where probabilistic incidence values are allocated for every taxon and their corresponding morpho-biochemical characters. Apiweb $^{\mathrm{TM}} \%$ ID is a probabilistic calculation using
bioMerieux own system procedure. The code of isolated strain of Gallibacterium anatis biovar haemolytica is Gah IDSA 161.

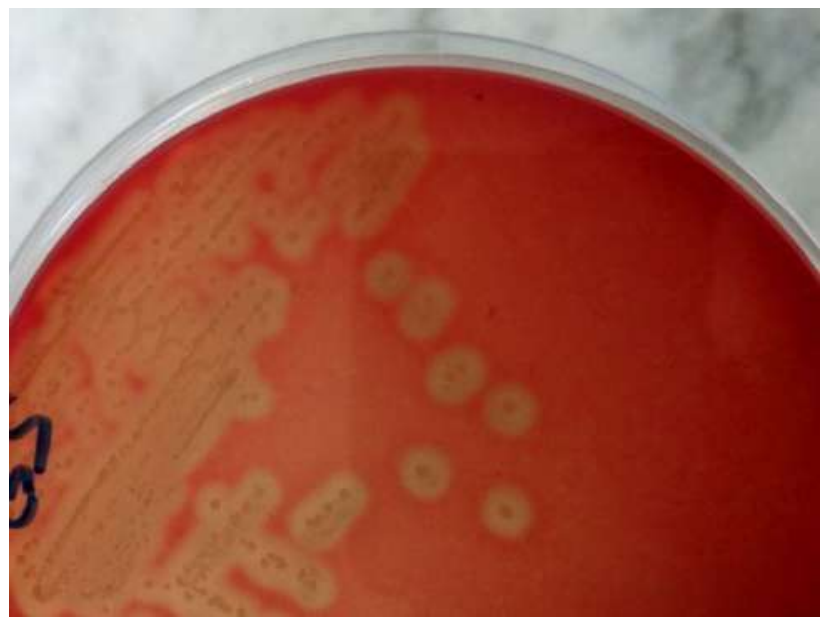

Figure 1. Gallibacterium anatis biovar haemolytica IDSA 161 strain on nutrient agar supplemented with 5\% sheep blood, after 48 hours of aerobic incubation at $37^{\circ} \mathrm{C}$.

The Gah IDSA 161 strain was susceptible to sulfonamide, sulfomethoxazole/trimethoprim, gentamicin, cephalothin, streptomycin, amoxicilin/clavulanic acid, moderate susceptible to erythromycin and was resistant to tetracycline, oxitetracycline, doxicyclin, trimethoprim, nalidixic acid, clindamycin, enrofloxacin, ciprofloxacin, ampicillin. In Table 1 are presented the diameter of inhibition zone for every tested antibiotic.

Table 1. The diameters of inhibition zones of Gallibacterium anatis biovar haemolytica Gah IDSA 161 strain for tested antibiotics.

\begin{tabular}{|c|l|c|c|}
\hline $\begin{array}{c}\text { No. } \\
\text { crt. }\end{array}$ & \multicolumn{1}{|c|}{ Antibiotic } & $\begin{array}{c}\text { Diameter of } \\
\text { inhibition } \\
\text { zone }(\mathrm{mm})\end{array}$ & Interpretation \\
\hline 1. & $\begin{array}{l}\text { Amoxicilin/acid } \\
\text { clavulanic }\end{array}$ & 21 & $\mathrm{~S}$ \\
\hline 2. & Ampicillin & 18 & $\mathrm{R}$ \\
\hline 3. & Cephalothin & 23 & $\mathrm{~S}$ \\
\hline 4. & Ciprofloxacin & 14 & $\mathrm{R}$ \\
\hline 5. & Clindamycin & 6 & $\mathrm{R}$ \\
\hline 6. & Doxicyclin & 9 & $\mathrm{R}$ \\
\hline 7. & Enrofloxacin & 6 & $\mathrm{R}$ \\
\hline 8. & Erythromycin & 15 & $\mathrm{MS}$ \\
\hline 9. & Gentamicin & 25 & $\mathrm{~S}$ \\
\hline 10. & Nalidixic acid & 6 & $\mathrm{R}$ \\
\hline 11. & Oxitetracycline & 6 & $\mathrm{R}$ \\
\hline 12. & Streptomycin & 19 & $\mathrm{~S}$ \\
\hline 13. & $\begin{array}{l}\text { Sulfomethoxazo } \\
\text { le/trimethoprim }\end{array}$ & 23 & $\mathrm{~S}$ \\
\hline 14. & Sulfonamide & 25 & $\mathrm{~S}$ \\
\hline 15. & Tetracycline & 6 & $\mathrm{R}$ \\
\hline 16. & Trimethoprim & 6 & $\mathrm{R}$ \\
\hline
\end{tabular}

$\mathrm{S}=$ susceptible, $\mathrm{MS}=$ moderate susceptible, $\mathrm{R}=$ resistant. 
G. anatis infection is, until recently, an underdiagnosed or ignored cause of economic losses and mortality in poultry (Krishnegowda et al., 2020), with a global distribution in Europe, Asia, Africa, Australia, North America and South America. So far, from our knowledge, there isn't any report of $G$. anatis infection in Romania.

The Gah IDSA 161 strain, isolated from a hen from a 30 birds flock, Ilfov county, Romania, could be phenotypic identified only by ABIS on line software, Pasteurellaceae Database version, unifying the results of API 20 E, API STAPH, API $20 \mathrm{NE}$ and API ZYM kits, and other biochemical tests. The indications that Gah IDSA 161 belongs to the Pasteurellaceae family are some morphologically (Gram-negative non-motile rods), culturally (facultative anaerobic) and biochemically (ability to reduce nitrate, oxidase- and phosphatase-positive tests) characters (Christensen et al., 2007). For the Gallibacterium genus taxonomic classified of the isolated strain, they were important catalase positive test, urease negative, indole negative, ONPG positive, $\mathrm{H}_{2} \mathrm{~S}$ negative, Simmon's citrate negative, Voges-Proskauer negative, arginin dihydrolase negative, lysine decarboxilase negative, ornithine decarboxilase negative, gelatinase negative, acid production positive from D-glucose, D-mannitol, D-fructose, mannose, sucrose, acid production negative from amygdalin, and negative reactions for $\beta$-glucuronidase, $\beta$-glucosidase, $\alpha$-mannosidase and $\alpha$-fucosidase. Gah IDSA 161 belongs the $G$. anatis biovar haemolytica being strong $\beta$-haemolytic, L-arabinose negative, $m$-inositol positive, D-sorbitol positive, Dmaltose negative, D-xylose positive and D-trehalose positive (Christensen et al., 2003). Comparing with the key characters for separation of the biovars of the avian $[P$. haemolytica]-,A. salpingitidis' complex, Gah IDSA 161 matches only with biovar 4 strains (L-arabinose negative, $m$-inositol positive, D-sorbitol positive, D-maltose negative, D-xylose positive and D-trehalose positive). The three strains of bv. 4 described, belonging G. anatis, were all associated with lessions at different birds [10672/9 Salp. (=F114), chicken, Denmark; Gerl. 2396/79 (=F465), chicken, Germany; 5821/88, parrot, Germany] (Christensen et al., 2003). However, there are, also, another strains of bv. 4, belonging $G$. melopsittaci species (F $416=$ HIM778-3, isolated from a parakeet with septicemia), $G$. salpingitidis (19987/2, from a goose with salpingitis and peritonitis) and Gallibacterium genomospecies 3 (F298, from a duck with septicemia) (Bisgaard et al., 2009). So, all the strains from bv. 4, apart of host, were associated with lessions.

Gah IDSA 161 differs from the emended description of the genus Gallibacterium Christensen et al., 2003 (Bisgaard et al., 2009) by test positive for production of acid from L-rhamnose. So, this character could be a phenotypic marker for the strain, together with above fermentative characters which include it in biovar 4 of former avian $[P$. haemolytica $]-, A$. salpingitidis' complex.

As for antibiotic susceptibility, Gah IDSA 161 has a similar profile, generally, with isolates from Germany (ElAdawy et al., 2018), which were susceptible to sulfomethoxazole/trimethoprim ( $80 \%$ of strains), gentamicin
$(73 \%)$, neomycin $(100 \%)$, apramycin $(100 \%)$, florphenicol $(100 \%)$, and all strains were resistant to oxitetracycline, clindamycin, penicillin, sulfathiazole, sulfamethoxim, spectinomycin and tylosin. Also, generally, Gah IDSA 161 has a similar profile with the isolates from Austria (Hess et al., 2019), which were susceptible to amoxicillin/ clavulanate (99\% of strains), ampicillin (79\%), amoxicillin (69\%), gentamicin $(93,9 \%)$, streptomycin $(96,7 \%)$, cefotaxime $(82 \%)$, colistin $(75 \%)$, imipenem $(83,5 \%)$, neomycin $(59,6 \%)$, and were resistant to oxacillin $(98 \%)$, tylosin (94\%), tetracycline (89\%), nalidixic acid (77\%), sulfamethoxazole $(77 \%)$, sulfomethoxazole/ trimethoprim (61\%), enrofloxacin (58\%). The isolates of $G$. anatis from Denmark and Mexic were resistant to tetracycline (92\% of strains) and sulfamethoxazole (97\%) and were susceptible to quinolones (Bojesen et al., 2011). Multi-drug resistant isolates of this species are frequently reported, with resistance to clindamycin, sulfonamides, novobiocin, tylosin, penicillin, and tetracycline (Krishnegowda et al., 2020). So, since antimicrobial susceptibility of isolates constantly changes, in vitro testing of the strains is often needed.

\section{Conclusion}

Has been isolated and phenotypically identified a strain of $G$. anatis biovar haemolytica from a hen with hemorrhagic ooforitis. From our knowledge, this is the first reporting in Romania of isolation and identification of $G$. anatis biovar haemolytica. This isolate, Gah IDSA 161, differs from the emended description of the genus Gallibacterium Christensen et al., 2003 (Bisgaard et al., 2009) by test positive for production of acid from L-rhamnose. So, this character could be a phenotypic marker for the strain, together with some fermentative characters which include it in biovar 4 of former avian $[P$. haemolytica]-,A. salpingitidis' complex (L-arabinose negative, $m$-inositol positive, D-sorbitol positive, D-maltose negative, D-xylose positive and D-trehalose positive). The Gah IDSA 161 strain showed a multi-drug resistant profile to tetracyclines (tetracycline, oxitetracycline, doxicyclin), floroquinolones (enrofloxacin, ciprofloxacin), ampicillin, trimethoprim, nalidixic acid, clindamycin, and it was susceptible to sulfonamide, sulfomethoxazole/ trimethoprim, gentamicin, cephalothin, streptomycin, amoxicilin/clavulanic acid. This profile was similar, generally, with the one of isolates from Germany (El-Adawy et al., 2018) and Austria (Hess et al., 2019).

\section{Acknowledgment}

The authors have no conflict of interest to report.

We thank assistant Marin Domnica for her excellent technical assistance.

\section{References}

1. Alispahic M, Christensen H, Hess C., Razzazi-Fazeli $\mathrm{E}$ et al. MALDI-TOF mass spectrometry confirms clonal lineages of Gallibacterium anatis between chicken flocks. Vet Microbiol. 2012; 160: 269-273. doi: $10.1016 /$ j.vetmic. 2012.05 .032 . 
2. Aubin GG, Haloun A., Treilhaud M, Reynaud A, Corvec S. Gallibacterium anatis bacteremia in a human. J Clin Microbiol. 2013; 51(11): 3897-3899. doi: 10.1128/JCM.01638-13.

3. Bisgaard M, Korczak BM, Busse HJ, Kuhnert P et al. Classification of the taxon 2 and taxon 3 complex of Bisgaard within Gallibacterium and description of Gallibacterium melopsittaci sp. nov., Gallibacterium trehalosifermentans sp. nov. and Gallibacterium salpingitidis sp. nov. Int J Syst Evol Microbiol. 2009; 59: 735-744. doi: 10.1099/ijs.0.005694-0.

4. Bojesen AM, Nielsen SS, Bisgaard M. Prevalence and transmission of haemolytic Gallibacterium species in chicken production systems with different biosecurity levels. Avian Pathol. 2003a; 32(5): 503-510. doi: 10.1080/ 0307945031000154107.

5. Bojesen AM, Christensen H, Nielsen OL, Olsen JE, Bisgaard M. Detection of Gallibacterium spp. in chickens by fluorescent 16S rRNA in situ hybridization. J Clin Microbiol. 2003b; 41(11): 51675172. doi: 10.1128/JCM.41.11.5167-5172.2003.

6. Bojesen AM, Vasquez ME, Bager RJ, Ifrah D et al. Antimicrobial susceptibility and tetracycline resistance determinant genotyping of Gallibacterium anatis. Vet Microbiol. 2011; 148: 105-110. doi: 10.1016/j.vetmic. 2010.08.011.

7. Christensen H, Bisgaard M, Bojesen AM, Mutters R, Olsen JE. Genetic relationships among avian isolates classified as Pasteurella haemolytica, 'Actinobacillus salpingitidis' or Pasteurella anatis with proposal of Gallibacterium anatis gen. nov., comb. nov. and description of additional genomospecies within Gallibacterium gen. nov. Int J Syst Evol Microbiol. 2003; 53: 275-287. doi: 10.1099/ijs.0.02330-0.

8. Christensen H, Kuhnert P, Busse HJ, Frederiksen WC, Bisgaard M. Proposed minimal standards for the description of genera, species and subspecies of the Pasteurellaceae. Int J Syst Evol Microbiol. 2007; 57: 166-178. doi: 10.1099/ijs.0.64838-0.

9. Clinical Laboratory Standards Institute (National Committee for Clinical Laboratory Standards). Performance Standards for Antimicrobial Disk and Dilution Susceptibility Tests for Bacteria Isolated from Animals - second edition: Approved Standard M31-A2. 2002; CLSI, Wayne, PA, USA.

10. CLSI. Performance Standards for Antimicrobial Disk and Dilution Susceptibility Tests for Bacteria Isolated from Animals, 4 ${ }^{\text {th }}$ ed.; CLSI Supplement VET08.
2018; Clinical and Laboratory Standards Institute: Wayne, PA, USA.

11. CLSI. Performance Standards for Antimicrobial Susceptibility Testing, $30^{\text {th }}$ ed.; CLSI Supplement M100. 2020; Clinical and Laboratory Standards Institute: Wayne, PA, USA.

12. El-Adawy H, Bocklisch H, Neubauer H, Hafez HM, Hotzel H. Identification, differentiation and antibiotic susceptibility of Gallibacterium isolates from diseased poultry. Ir Vet J. 2018; 71: 5-14. doi: 10.1186/ s13620018-0116-2.

13. Hess C, Grafl B, Bagheri S, Kaesbohrer A, Zloch A, Hess M. Antimicrobial resistance profiling of Gallibacterium anatis from layers reveals high number of multiresistant strains and substantial variability even between isolates from the same organ. Microb Drug Resist. 2019. doi: 10.1089/mdr. 2019.0056.

14. Krishnegowda DN, Dhama K, Mariappan AK, Munuswamy P et al. Etiology, epidemiology, pathology, and advances in diagnosis, vaccine development, and treatment of Gallibacterium anatis infection in poultry: a review. Vet Quart. 2020; 40(1): 16-34. doi: 10.1080/ 01652176. 2020.1712495.

15. Paudel S, Alispahic M, Liebhart D, Hess M, Hess C. Assessing pathogenicity of Gallibacterium anatis in a natural infection model: the respiratory and reproductive tracts of chickens are targets for bacterial colonization. Avian Pathol. 2013; 42(6): 527-535. doi: 10.1080/03079457.2013.843160.

16. Persson G, Bojesen AM. Bacterial determinants of importance in the virulence of Gallibacterium anatis in poultry. Vet Res. 2015; 46: 57-67. doi: 10.1186/ s13567-015-0206-z.

17. Rzewuska M, Karpinska E, Szeleszczuk P, Binek M. Isolation of Gallibacterium spp. from peacocks with respiratory tract infections. Med Wet. 2007; 63(11) Supplement: 1431-1433.

18. Stoica C, Sorescu I. ABIS online-Advanced Bacterial Identification Software, an original tool for phenotypic bacterial identification. Regnum Prokaryotae. Available online: www.tgw1916.net (accesed on 19.06.2020).

19. Wang C, Robles F, Ramirez S, Riber AB, Bojesen AM. Culture-independent identification and quantification of Gallibacterium anatis ( $G$. anatis) by real-time quantitative PCR. Avian Pathol. 2016; 45(5): 538-544. doi: 10.1080/03079457.2016.1184743 